\title{
A UNIPOLAR CONCENTRATION OF ENGLISH AND THE MULTILINGUAL-SEMILINGUAL PARADOX
}

\author{
Fusa Katada \\ Waseda University, Faculty of Science and Engineering \\ 3-4-1 Okubo, Shinjuku-ku, Tokyo 169-8555 Japan
}

\begin{abstract}
'We have the right to talk and think in our own language.' This self-evident slogan is ever challenged in the digital age of the 21 st century. 'Talking and thinking' is most effectively trained and achieved by formal education carried out in one's own language. However, multilingual children growing up in multilingual societies would have to adjust their own language to a language of education in schooling. This paper clarifies scientific grounds that in such situations the main root of learning and thinking through language is discontinuous. It is claimed that the students may face semilingualism, defined as 'linguistic competence insufficiently developed for complex conceptual thinking'. Multilingualism and semilingualism are two sides of one coin, and semilingualism is affecting many parts of the world. This is due to the established eminence of English as a global lingua franca (ELF), which serves as their language of education. This paper is qualitative in nature, pointing out discrepancies between the politically empowered unipolar concentration of English and cognitively suited languages for sustainable development of conceptual thinking. It is intended to serve as a reference point for educators and professionals who are responsible for raising human resources in the digitalized global age.
\end{abstract}

\section{KEYWORDS}

Multilingualism, Semilingualism, Language for Conceptual Thinking, Mother-tongue-based Education

\section{INTRODUCTION}

Believing in the importance of cultural and linguistic diversity for sustainable societies, the General Conference of UNESCO approved February 21 as International Mother Language Day, a day to celebrate all mother languages spoken in the world (UNESCO Paris, 1999). The idea is to promote linguistic and cultural diversity and multilingualism in all aspects of public life, and particularly in education (UNESCO Bangkok, 2005). This conforms to the growing awareness of the importance of promoting primary education in children's mother language (UNESCO, 2010). However, there are nearly 7,000 languages currently spoken in the world (Gordon, Jr., 2005), so it is unrealistic to expect that every child can be educated in his/her mother language. Given the established eminence of English as a global lingua franca (ELF), it seems inevitable that multilingual communities choose English as their language of education. What problems then do children encounter when the school language is not the same as their mother language?

This paper clarifies scientific grounds for why mother-tongue-based education is important for sustainable development of conceptually complex thinking and that when children face schooling in a language other than their own, the main root of learning and thinking is discontinuous. It is claimed that the students may face the semilingual state of mind, defined as 'linguistic competence insufficiently developed for conceptual thinking'. Multilingualism and semilingualism are two sides of one coin. Due to the politically empowered unipolar concentration of English, English has come to be the world second language that serves as the language of education in many multilingual communities. Semilingualism is thus a global issue now.

This paper is qualitative in nature. It is expected to serve as a conceptual reference point for educators and professionals who are responsible for raising human resources in the digitalized global age. It also intends to raise the term 'semilingualism' to the level of academic terminology, so that research on this serious state of mind may advance further. 


\section{THE MULTILINGUAL-SEMILINGUAL PARADOX}

\subsection{IMLD (UNESCO 1999) and the Gravity of Mother-tongue-based Education}

Shaheed Minar is a martyr monument at the University of Dhaka, which commemorates people who demonstrated for the recognition of Bengali as one of the two national languages of East Pakistan (the other was Urdu) and were shot dead by police in the capital of present-day Bangladesh. This disaster happened on 21 February, 1952. Nearly a half century after this incident, on 17 November, 1999, the General Conference of UNESCO proclaimed 21 February as International Mother Language Day (IMLD), a symbolic day to celebrate language diversity, to promote the preservation and protection of all languages used by people of the world.

The UNESCO office in Bangkok (2005) uttered a message that stresses the role of language in education for sustainable development of societies; there is a growing awareness that languages play a vital role in process of integration into all aspects of public life but particularly in education; the awareness strengthens co-operation and contributes to attaining quality education for all, building inclusive knowledge of societies and preserving cultural heritage, and mobilizing political will to apply the benefits of science and technology to sustainable development; supporting language diversity is also about supporting inclusion and acknowledging that language diversity helps to enrich us all, that this diversity of language is a treasure, not a barrier.

Language in 'language diversity' virtually means 'mother-tongue' (that is, the child's first language, L1) spoken in the world. Below are teachers' voices for mother-tongue based education that have been publicized by the UNESCO office.

"Mother tongue education is not translation-teaching. It is a teaching method that uses children's mother tongue language for the medium of education to stimulate their cognitive skills, creative skills, and confidence." (Suraida A-wae, a Patani-Malay speaker in Thailand)

"Mother tongue education is like the lower rungs of the ladder. Without it, children are trying to jump up onto the higher rungs and often fall in the attempt." (Gohar Rahman, a Gawri speaker in Pakistan)

The UNESCO office continued that in the context of education it is impossible to teach the majority of people to read and write in a language they don't understand, and that it is easier for you to learn a second language if you have learnt your first language well.

This message recognizes the difficulty of promoting education in all mother languages spoken in the world. Multilingual communities would have to go through contraction of the multiple local languages (mother-tongues) to just a few languages to carry out education, and these languages are learnt as their second language (L2).

\subsection{A Unipolar Concentration of English as a Second Language of the World}

Given the established eminence of English as a global lingua franca (EFL) especially in academic discourse in the 21st century, it seems inevitable that English is chosen as their language of instruction, which is equivalent to a second language in the above UNESCO's suggestion. Evidently this appears in another teacher's voice:

"Learning English is important to be globally competitive, but we have to consider that the main root of learning is through our first language." (Rasmila M. Cosain, a Maranao speaker in the Philippines)

In these UNESCO's messages and teachers' voices, it is given as self-evident that mother-tongue based education (MTBE) is important and with no specific evidence. To see related issues and problems, the importance of MTBE should be grounded scientifically. The next section clarifies why MTBE is so important when everyone seems to agree that English is important as a global language of the world. 


\subsection{Scientific Bases for Mother-tongue-based Formal Education}

\subsubsection{Verbal Thought: L.S. Vygotsky Revisited}

In his most influential theory of child development, Vygotsky (1934) claims that thought and speech have different genetic roots. At around 2 years from the child's birth, thought and speech begin to join to initiate a new form that is distinct from either thought or speech. According to him, a prelinguistic phase in the development of thought and a preintellectual phase in the development of speech are externally observable. This is because younger children are only really able to "think out loud." At around 3 to 4 years of age, ego-centric speech appears, which is an observable sign for thought and speech coming together to join. It lasts for a few years and then disappears at around 6 to 7 years of age. The disappearance of ego-centric speech is a sign that the merger of the linguistic phase and the intellectual phase is completed. When the two phases are merged, thought becomes verbal in a form known as thought in language, and speech is rational. Afterwards, due to its ability to bear concepts, language organizes thinking.

Note that, in most of the world school systems, 6 to 7 years old accords with the age when primary schooling begins. It is inevitable that a sprouting oral ability for thought in language is a presupposition to formal education.

\subsubsection{Written Language in School for Cognitive Development: J.S. Bruner Revisited}

Based on the study on schooled vs. unschooled children among the Wolof in Senegal, Bruner $(1966 ; 1971)$ stresses the importance of written language in school. He claims that schooling and exposure have a significant effect on the development of the ability to perform more sophisticated cognitive operations: categorization and preservation problems. The hypothesis here is that school is operating on grouping operations through the training embodied in written language. This hypothesis has a theoretical base; that is, the written language provides an occasion in which one must deploy language out of the immediate context of reference. Writing virtually forces a remoteness of reference on the language user. In other words, writing is training in the use of linguistic contexts that are independent of immediate context, and moreover, understanding and expressing in written language is training for the development of thought. Note that literacy, as opposed to orality, is a key to formal education.

\subsubsection{The Rationale for Mother-Tongue-Based Formal Education}

The fusion of a prelinguistic phase and a preintellectual phase is an age appropriate cognitive developmental phenomenon that takes place at around 2 to 3 years old; the fusion comes to its completion at around 6 to 7 years old; and primary schooling begins. For sustainable development of the child's learning, it would be ideal if the language acquired early enough be used continuously in school as a medium of instruction. This is because such a language has most likely been gone through the ego-centric speech; it can be assumed to be tightly fused with thought; and thus it functions best as a tool for thinking. As Figure 1 illustrates, such a language is the child's mother-tongue (i.e. his/her L1) acquired and used before 6-7 years old.

\begin{tabular}{|lllllllllllllll|}
\hline 0 & $\mathbf{1}$ & $\mathbf{2}$ & $\mathbf{3}$ & $\mathbf{4}$ & $\mathbf{5}$ & $\mathbf{6}$ & $\mathbf{7}$ & 8 & 9 & 10 & 11 & 12 & $\ldots$ & (age) \\
$\mathrm{L} 1$ & & & & & & & & & &
\end{tabular}

Figure 1. Age line and L1 as a language of education

For the child to be trained in written language in school, his/her L1 must be a written language having its own script. It is thus apparent that an ideal situation is created when two conditions (1) and (2) are met:

(1) the mother-tongue (L1) serves as a language of education, and

(2) the mother-tongue (L1) is a written language, having its own script.

By (1) verbal though in the mother-tongue is ensured. By (2) textbooks can be developed in the mother-tongue, and training for the development of thought in written language is ensured. We may then expect that the main root of learning, shaped up by literacy-based formal education, grow continuously throughout life. 
Simplest cases that meet the two conditions may be found in monolingual communities with literacy traditions. For example, the Japanese culture has been considered near monolingual and meets the two conditions: (1) the child's mother-tongue, which is Japanese, is continuously used as a language of education in all levels of education, from elementary to higher education, and (2) Japanese is a written language, having its own scripts (Kanji and Kana) used for centuries. It is anticipated that on the basis of Japanese as the language of education, the main root of learning in Japanese, shaped up by literacy based formal education, can continuously grow. However note that due to the globalized movements of people, it is no longer true that Japan is a monolingual society. The country embodies multilingual populations and it is subjected to all issues raised in this paper.

\subsubsection{Confirmation from School Sites}

In her summary of mother-tongue based bilingual/multilingual education, Ball (2010) refers to the studies by Thomas \& Collier (2002), which show that six to eight years of education in a language are necessary to develop the level of literacy and verbal proficiency required for academic achievement in secondary school. Research shows that children's ability to learn a second or additional languages (e.g., a lingua franca and an international language) does not suffer when their mother tongue is the primary language of instruction throughout primary school. Fluency and literacy in the mother tongue lay a cognitive and linguistic foundation for learning additional languages. When children receive formal instruction in their first language throughout primary school and then gradually transit to academic learning in the second language, they learn the second language quickly. If they continue to have opportunities to develop their first language skills in secondary school, they emerge as fully bilingual (or multilingual) learners.

Key to the successful bilingualism (or multilingualism) in learning seems to be the mother-tongue based (MTB) instruction throughout primary schooling. Reality, however, is that many parts of the world are not ensured the MTB instruction, especially due to the linguistic complexity.

\subsection{Multilingualism and Semilingualism as Two Sides of One Coin}

\subsubsection{Extraordinary Multilingual Communities: One Representative Case from the Philippines}

The Philippines is an archipelago nation consisting of over 7,000 islands, positioned off the southeastern coast of Asia, directly east of Vietnam and northeast of Malaysia. The nation covers $298,170 \mathrm{~km}^{2}$ and has a population counting nearly 105 million. 182 living languages are identified, 175 among which are indigenous languages, abbreviated here as IP-language. Official languages are Filipino (the standardized version of Tagalog) and English. About 19 IP-languages are designated as auxiliary official languages and used as a language of education for the first 3 years of primary education before English comes into play. For the majority of children in the nation, IP-languages (their mother-tongues) are not used in school.

The area on which this study reports is Davao del Sur in Mindanao, the southern island of the Philippines. The area has a population of 633,000 and at least 40 indigenous languages are spoken. The language environment surrounding children in the school district is summarized in Table 1.

Table 1. Language environment surrounding children in Davao del Sur

\begin{tabular}{lll}
\hline & Language used & Nature of language \\
\hline L1 & IP-language & Mother-tongue spoken at home \\
L2 & Bisaya & Neighborhood language \\
L3 & Cebuano & Language of education from Grade 1 to 3 \\
L4 & Filipino & National language, taught from Grade 1 \\
L5 & English & Language of education from Grade 4, onward \\
\hline
\end{tabular}

First, children are born and raised in diverse mother-tongue (L1) environments. They are then exposed to Bisaya (L2), a neighborhood language, when they are grown big enough to be around outside, at about 2 years old. Elementary school education is carried out in Cebuano from Grade 1 to Grade 3. Thus, children, unless their mother-tongue is Cebuano, must switch from their mother-tongue (L1) to Cebuano (L3) for the first three years of elementary schooling. The teachers are not always the speakers of the children's mother tongues; thus, the teacher-student communication is usually difficult. In addition, Filipino (the standardized 
version of Tagalog) is designated as the national language; it is one of the subjects taught to children from Grade 1 and onward; Filipino is their fourth language (L4). Finally, in Grade 4, the language of education is switched from Cebuano to English; English is their fifth language (L5). For the rest of the education system throughout the nation, English serves as a 'medium of instruction'.

\subsubsection{Problems Anticipated in Multilingual Communities}

Linguistic complexities in the area described in the previous section is schematically shown in Figure 2.

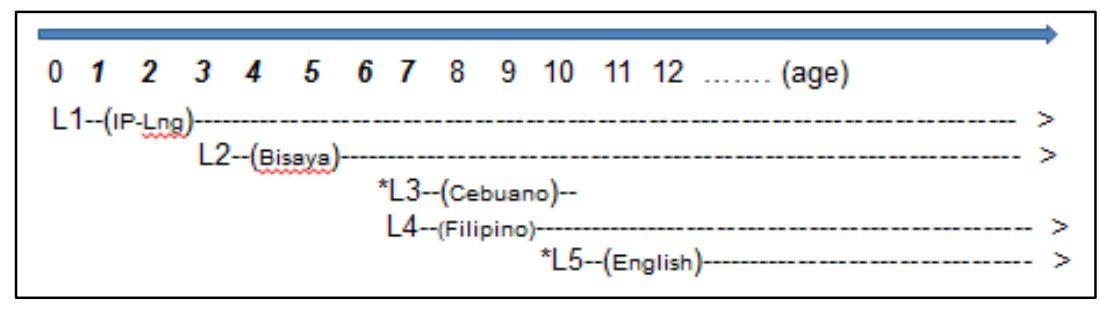

Figure 2. Linguistic complexities: an example from Davao del Sur

What would happen then to the main root of learning in children living with such complexities?

The apparent anticipation is the following. First, the fusion of a prelinguistic phase and preintellectual phase proceeds through the children's IP-language spoken at home (that is their L1) or Bisaya (their L2) to which children are exposed early enough in the neighborhood. In other words, a language that is ready to organize thinking in them would be their IP-language or Bisaya. Either of them, however, is used as a language of education; the first three years of primary schooling (Grade 1-3) is carried out in Cebuano, which is switched to English in the fourth year (Grade 4). It can be anticipated that the main root of learning, to be shaped up by formal education, is discontinuous twice in the early schoolhood: once, upon the entrance to of the elementary school when children encounter Cebuano, and twice, in the beginning of the 4th year when Cebuano is taken over by English for the rest of their schooling. It is obvious that English is not an ideal, most natural language for the children to develop verbal thought (or conceptual thinking) in. Although language is not the only factor affecting learning abilities, a linguistic factor remains most influential in the children's sustainable cognitive development.

\subsubsection{Defining Semilingualism}

Children living in multilingual communities may be multilingual performers but only at the conversational level. Their verbal thought is not necessarily ensured to fully develop in all languages they have learnt to speak. Here, two levels of language faculty are proposed: the language of thought and the language of communication. The term semilingualism is suggested here to refer to the cognitive linguistic state of the child's learning foundation. Semilingual is defined as 'linguistic competence insufficiently developed for complex conceptual thinking'. In short, people may be multilingual at the level of conversation but semilingual at the level of verbal thought. In other words, semilingualism may be hidden in multilingualism; they are two sides of one coin.

In educational settings, language diversity (i.e. mother-tongue diversity) must be reduced to just a few languages of instruction, which may be referred to as language contraction. The children whose mother-tongue is not the same as the language of education may fall in the above defined semilingualism. This pitfall is a challenge to the principle of International Mother Language Day, which stresses the importance of language in education. Given English as the virtual second language of the world which plays a role of language of education, semilingualism must be a universal concern in the digitalized age.

\section{MATHEMATICAL REPRESENTATIONS}

An apparent shortcoming of the study presented so far is that there is no scientific evidence we may provide for the semilingual state of mind. Children's achievement in school in comparison among relevant groups of children such as in Bruner (1971) may constitute for one type of evidence. However, possible factors affecting the ability to learn is not only language. Strictly speaking then, it is difficult to narrow down 
possible parameters to just language and standardize levels of semilingualness. The purpose of this chapter is then to express the linguistic state of the child's mind in a mathematical format, taking up English representing a second language (L2) of the world, which functions as the language of education, as well as a global lingua franca (ELF) for communication purpose.

\subsection{Direct Communication in L1 vs. Indirect Communication in L2 (ELF)}

It is self-evident that it is the native speakers of a given language (L1) who enjoy their extraordinary linguistic competence in their language and all the benefits in social competition. In this sense, L1 belongs to the native speakers of this L1. English as a global lingua franca (ELF), on the other hand, is a product of the globalized discourse that can be characterized as a disembedded 'neutral' language of a communication means with no identification potential. There are no native speakers of ELF itself. In this sense ELF does not belong to anyone. This is another way of saying that ELF belongs to anyone who uses it. Languages other than the speakers' L1 and the speakers (or language users) can be expressed in functional forms. (The earliest formulation is presented in Katada (2019).)

In Figure 3, ELF is expressed as a function of L1, as in (a). A user of ELF (a non-native speaker of English) is in turn expressed as a function of ELF, as in (b), which is a function of L1. A native speaker of L1 is a function of this L1, as in (c).
(a) $\operatorname{ELF}\left(\operatorname{L1}_{\mathrm{i}}\right)$
(b) Speaker $\left\{\operatorname{ELF}\left(\mathrm{L}_{\mathrm{i}}\right)\right\}$
(c) Speaker $\left(\mathrm{L1}_{\mathrm{i}}\right)$

where $i$ ranges over diverse natural languages (mother-tongues)

Figure 3. Speaker as a Function of Language

Representation (a) yields varieties of ELF according to diverse natural languages spoken in the world $\left(\mathrm{L} 1_{\mathrm{i}}\right)$. In a conventional term this is what we call 'world Englishes'. In (b) a native language $\mathrm{L} 1_{\mathrm{i}}$ is embedded in ELF, which shows remoteness of $\mathrm{L} 1_{\mathrm{i}}$ to the speaker of $\mathrm{L} 1_{\mathrm{i}}$-based ELF. This is in contrast with directness of $\mathrm{L} 1_{\mathrm{i}}$ to its native speaker represented in (c). A source of frustration when the nonnative English speaker had to speak English can be read off in terms of this remoteness in (b).

Communication between two speakers of different native languages is illustrated in Figure 4. They communicate using ELF, which is a common linguistic means but with different L1-based. After all, ELF is a means to allow only indirect communication among people.

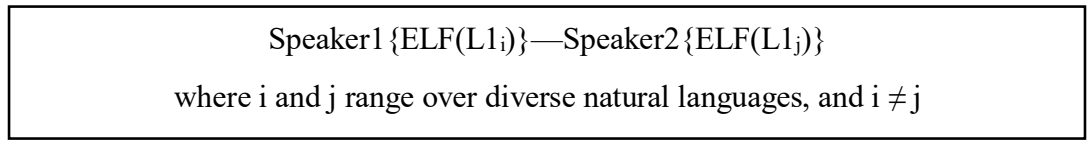

Figure 4. Indirect Communication via ELF (English as a Lingua Franca)

Indirect communication is in contrast with direct communication illustrated in Figure 5. Strictly speaking, direct communication is possible only between the speakers of the same native language (L1).

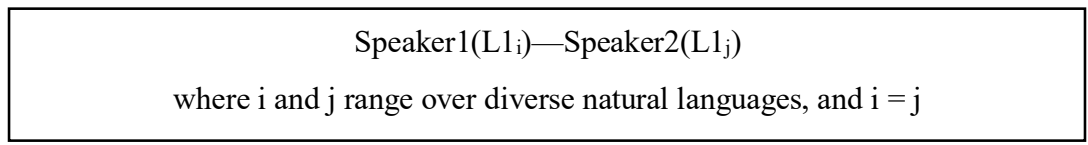

Figure 5. Direct Communication via the Same L1 (Mother-tongue)

\subsection{Direct vs. Indirect Access to Verbal Thought (Conceptual Thinking)}

Likewise for the educational settings, the child can be represented as a function of the language he/she uses. In Figure 6, (a) represents children who have direct access to the verbal thought in their L1 (mother-tongue), and (b) represents children who had to use a second language (L2), which is a function of their L1. 
(a) Child(L1): direct (strong) access to verbal thought via L1.

(b) Child $\{\mathrm{L} 2(\mathrm{~L} 1)\}$ : indirect (weak) access to verbal thought via L2

Figure 6. Access to Verbal Thought (Conceptual Thinking)

In other words, the access to verbal thought (conceptual thinking) through L2 (English) is indirect and thus weaker than it is through L1.

\section{CONCLUSION}

The current linguistic situation of the world may be expressed in terms of three Ds of a linguistic chain-linguistic diversity, linguistic disparity, and linguistic divide, which is developed from the earliest thought presented in Katada (2002). Linguistic diversity refers to the fact that nearly 7,000 languages are spoken on the globe (Gordon, Jr., 2005). Among them, only a few languages are chosen to function as languages of formal education. Due to its established eminence, English is a typical medium of instruction in the globalized age. English is not only a global lingua franca in higher academic discourse but also a language of education chosen for primary education in many multilingual communities. This triggers linguistic disparity against the nonnative English world where English is not an ideal language to develop verbal thought (conceptual thinking); the problem of semilingualism may arise, which is defined as 'linguistic competence insufficiently developed for complex conceptual thinking'. This is compared to the native English world where English is the mother-tongue (L1) that is naturally tied to verbal thought. In general, it is not easy to expect that the nonnative English world achieves the same level of English used for complex thinking. Education delivered in the form of English thus institutionalizes the disparity in thought development. The result is linguistic divide, a social outlook, which would affect people throughout life, from their student's life to their long coming professional life.

This paper is qualitative in nature. Scientific evidence for the semilingual state of mind is not easy to come by, and thus mathematical representations are provided. Research on the topic should advance further seeking relevant evidence. The students' performance records before and after the time when the mother-tongue-based education policy was adopted and its practice had begun in 2008 in the aforementioned area might constitute for one type of evidence. The language awareness questionnaire survey followed by Focus Group Discussion might contribute to constituting for another type of evidence for the linguistic state of mind. All possible research methodologies on semilingualism are completely open. The present paper is intended to serve as a conceptual reference point for concerned people including educators who are responsible for sustainable development of their students, professionals who face global competitions in the 21 st century, and language researchers and computer specialists who would try to elucidate the semilingual state of mind and seek for possible solutions with not excluding the possible use of advanced information technologies (cf. Katada, 2019).

\section{ACKNOWLEDGEMENT}

This study is supported by Japan Society for Promotion of Science (JSPS), Grant-in-Aid for Challenging Research (Exploratory) No. 19K21790 (Principal Investigator: Fusa Katada). My appreciation goes to Siverlyn Camposano at SPAMAST in Davao del Sur for her interest and collaboration for the planned advancement of research on the multilingual issues addressed in this paper. I would also like to thank two anonymous CELDA reviewers who furnished helpful referential comments. All shortcomings are mine. 


\section{REFERENCES}

Ball, J., 2010. Educational equity for children from diverse language backgrounds: mother tongue-based bilingual or multilingual education in the early years: summary. Presentation to UNESCO International Symposium: Translation and Cultural Mediation, Paris: UNESCO, 22/23 February 2010, on the occasion of the 11th International Mother Language Day in collaboration with the International Association for Translation and Intercultural Studies, 2010 International Year for the Rapprochement of Cultures. Retrieved 25 April 2019 from: http://dspace.library.uvic.ca/handle/1828/2457.

Bruner, J.S., 1966. Toward a Theory of Instruction. Harvard University Press, Cambridge, Massachusetts, USA.

Bruner, J.S., 1971. The Relevance of Education. W.W. Norton and Company Inc., New York, USA.

Gordon, R.G., Jr., 2005. Ethnologue: Languages of the World, 15th Edition. SIL International, Dallas, Texas, USA.

Katada, F., 2002. The linguistic divide, autolinguals, and the notion of education-for-all. Proceedings of the International Conference on Computers in Education. DOI: 10.1109/CIE.2002.1186327.

Katada, F., 2019. Autolingualism in the digital age: the emergence of cyber lingua franca and its impact on language education. Society for Information Technology \& Teacher Education International Conference 2019. 1520-1528.

Thomas, W.P. and Collier, V.P., 2002. A national study of school effectiveness for language minority students' long-term academic achievement. Goerge Masan University, Center for Research on Education, Diversity \& Excellence. Retrieved 18 November 2009 from: http://www/crede.ucsc.edu/research/llaa/1.1_final.html.

Vygotsky, L.S., 1934. Мылиление и речь. (Thought and Language, edited and translated by Hanfmann, E. and Vakar, G., 1962. MIT Press, Cambridge, Massachusetts and Wiley, New York, USA.

UNESCO, 1999. Draft Report of Commission, p.38. UNESCO, Paris, France.

UNESCO, 2005. Advocacy Belief on Mother Tongue-based Teaching and Education for Girls. UNESCO, Bangkok, Thailand.

UNESCO, 2010. Why and How Africa Should Invest in African Languages and Multilingual Education: An Evidence- and Practice-based Policy Advocacy Brief. UNESCO Institute for Lifelong learning, Hamburg, Germany. 